\title{
Un nuevo significado del topónimo España
}

\author{
DEREK W. LOMAX *
}

Durante la Edad Media, muchos cronistas y notarios de los reinos cristianos de la Península ibérica solían emplear el topónimo Hispania o España con dos significados diferentes, refiriéndose a veces a la Península entera, con sus islas adyacentes, y a veces al al-Andalus, es decir, a la región peninsular dominada por los musulmanes. Fue el Padre Flórez el primero en observar esta curiosa costumbre lingüística, y después varios historiadores la han analizado o la han tomado como base para especulaciones metahistóricas. Hoy por hoy, el mejor estudio se encuentra en las páginas que le dedicó al asunto el profesor J.A. Maravall hace un cuarto de siglo en su magistral libro sobre el concepto de España en la Edad Media .

En este libro, rechaza varias teorías de Giménez Soler y otros medievalistas, que no es del caso analizar aquí, y llega a la conclusión de que al menos desde el siglo Ix en Asturias, desde el $x$ en Córdoba y desde el XI en Cataluña y Aragón, se empleaba la palabra Hispania (en forma latina, castellana $u$ otra) en ambos sentidos, para indicar la Península entera, o para indicar al-Andalus. También nota el empleo por escritores cristianos de las palabras Córdoba y, desde el siglo XIII, Andalus, para indicar la España musulmana: y sugiere que a veces se empleaba la palabra España para indicar específicamente la región de la Península dominada por los cristianos. Esta última sugerencia es quizás menos

\footnotetext{
Universidad de Birmingham. 243.

J.M. Maravall: El concepto de España en la edad media, Madrid 1964, págs. 222 -
} 
convincente: los casos que cita son pocos, y la mayoría de ellos podrían interpretarse también con el sentido de la Península entera.

Sin embargo, su tesis general parece irrebatible; y, de hecho, el empleo de un solo topónimo para indicar tanto un país entero como una región política dentro del país no es tan raro como podría parecer. Conocemos muy bien la vida del Rey Alfredo de Wessex (871-899), porque se conserva su biografía, escrita poco después de su muerte por su amigo galés, Asser, obispo de Sherborne. En esta biografía, Asser emplea la palabra Britannia con dos sentidos. A veces la emplea para indicar toda la isla de Gran Bretaña, explicando, por ejemplo, que en el año 866 "una gran flota de vikingos llego a Britannia y pasó el invierno en el reino de los sajones orientales, que se llama en lengua anglo-sajona East Anglia»; y en otra ocasión explica que la ciudad de Exeter "está situada cerca del mar meridional que lava Galia y Britannia ${ }^{2}$ ". En cambio, en otras ocasiones emplea la palabra Britannia en el sentido, mucho más restringido, del País de Gales, de donde Asser mismo era natural. Así, refiriéndose al Offa's Dyke, frontera multisecular entre el País de Gales e Inglaterra, dice «el rey llamado Offa que mando construir una gran muralla entre Britannia y Mercia, de un mar a otro." Mercia era, como se sabe, el reino que ocupaba toda la región central de Inglaterra en el siglo noveno; y en otra ocasión Asser explica que «Burgredo, rey de los mercianos, pidió a Ethelwulfo, rey de Wessex, que le ayudara a someter a los britones centrales, que vivían entre Mercia y el mar occidental y que luchaban denodadamente contra él. Al recibir este mensaje, el rey Ethelwulfo llamó a su ejército, entró en Britannia con el rey Burgredo, devastó inmediatamente a aquella gente y la sometió al dominio de Burgredo.» ${ }^{3}$.

Este empleo de Britannia es, en cierta medida, paralelo al uso de Hispania en los textos hispánicos, aunque parece más lógico que los

2 W.H. Stevenson: Asser's Life of King Alfred, Oxford 1904, pág. 19: «Eodem anno magna paganorum classis de Danuia Britanniam advenit, et in regno Orientalium Saxonum, quod Saxonice "East-Engle" dicitur, hiemavit»; pág. 38: "Civitas Exae, quae in orientali ripa fluminis Uuisc sita est, prope mare meridianum, quod interluit Galliam Britanniamque.»

3 Ibidem, pág. 12: "Rex, nomine Offa, qui vallum magnum inter Britanniam atque Merciam de mari usque ad mare fieri imperavit"; págs. 6-7: «Burgred, Merciorum rex, per nuncios deprecatus et Aethelwulfum, Occidentalium Saxonum regem, ut ei auxilium conferret, quo mediterraneos Britones, qui inter Merciam et mare occidentale habitant, dominio suo subdere potuisset, qui contra eum immodice reluctabantur. Nec segnius Aethelwulfus rex, legatione eius accepta, exercitum movens, Britanniam cum Burghredo rege adiit, statimque ut ingreditur, gentem illam devastans, dominio Burgredi subdit." Para más ejemplos del empleo de Britannia y sus derivados con el sentido de Gales y galés, véanse las páginas $8,24,37,45$ y 47 . 
antiguos dueños de una país empleen el nombre del país entero para indicar el reducto montañoso donde se habían refugiado ellos a la manera de Asser, que emplearlo a la manera hispánica para describir precisamente aquella región del país ocupada por los invasores.

Ahora bien, además de los dos significados que se encuentran en el Occidente para los topónimos Hispania y Britannia, se puede encontrar en ciertas crónicas de las cruzadas otro empleo de la palabra Hispania.

El 21 de octubre de 1097, los cristianos de la primera cruzada llegaron a Antioquía y empezaron a sitiarla; pero llegó la Navidad de dicho año, la enorme ciudad seguía sin rendirse y lo sitiadores padecían un hambre atroz. Los jefes de la cruzada decidieron que el príncipe Boamundo de Taranto y el Conde Roberto II de Flandes fuesen a buscar provisiones en las aldeas de la región, dejando en el cerco de Antioquía al Conde de Tolosa, Raimundo IV de Saint-Gilles. Boamundo y Roberto llevaron sus tropas, unos veinte mil hombres, hacia el sur por el valle del río Orontes; y el 31 de diciembre se enfrentaron cerca del pueblo de Albara con un ejército musulmán que había salido de Damasco para levantar el sitio de Antioquía. Los cruzados consiguieron vencer, pero tuvieron que volver a Antioquía sin obtener las grandes provisiones que habian buscado ${ }^{4}$.

Varios cronistas de la primera cruzada relatan este incidente, y en términos bastante parecidos. Así, el clérigo Pedro Tudebodo, que participó en toda la primera cruzada, dice:

«Celebratis itaque gloriosissime sollempnitatibus Nativitatis, in die lune scilicet secunda feria, egressi sunt illi et alii plus quam viginti milia militum et peditum, terni, sani et incolupni intraverunt Sarracenorum terram" 5 .

Otro testigo ocular, el autor anónimo de la Gesta Francorum, emplea las mismas palabras, terminando con «intraverunt terram Sarracenorum»; y se encuentran frases parecidas entre los cronistas contemporáneos. Así

4 S. Runciman: A History of the Crusades. vol. I., Cambridge 1951, págs. 219-221.

5 Petrus Tudebodus: Historia de Hierosolymitano itinere, ed. J.H. Hill y L.L. Hill, Paris 1977, pág. 66: también en Recueil des historiens des Croisades. Historiens Occidentaux (desde ahora citado como RHC Occ), vol. III, Paris 1866, pág. 243. 
Roberto el Monje de Reims dice «boamundus et comes Flandrensis... in terram Sarracenorum intraverunt»; y Baldrico, arzobispo de Dol, dice «dispersi sunt per Sarracenorum colonias». Más tarde, Guillermo, arzobispo de Tiro, emplea las palabras "Visum est expedientius ut quidam de magnatibus, assumpta secum exercitus parte, hostium terras ingrederentur, ut inde sibi praedam et victui deferrent necessaria» ${ }^{6}$.

En cambio, Raimundo de Aguilers, capellán del Conde Raimundo IV de Tolosas y acompañante suyo en la primera cruzada, describe la misma expedición pero con una palabra sorprendente: "Comque iam in tercio mense obsidionis carius alimonia mercarentur, electus est Boamundus et Flandrensis comes ut exercitum propter victualia in Hispaniam ducerent, comite et episcopo Podiensi preside relicto in castris." $Y$, unas líneas más abajo, al referirse a la victoria cristiana de Albara, dice «Deus... exercitum nostrum in Ispaniis eodem tempore letificavit»?.

Antioquía cayó en manos de los cruzados en 3 de junio de 1097; y el 12 de diciembre capturaron la ciudad de Maarat al-Numan, donde se detuvieron un mes, mientras que los jefes de la cruzada discutían sus planes futuros, y los demás cruzados padecían tanta hambre que comían los cadáveres de los musulmanes. Finalmente el Conde Raimundo se negó a demorarse allí por más tiempo. Mandó que los cruzados realizasen expediciones de saqueo por el territorio circundante para recoger provisiones, luego incendió la ciudad de Maarat al-Numan y marchó hacia Jerusalén con cuantos quisieron seguirle. Entonces los príncipes árabes que gobernaban varias ciudades al sur de Maarat al-Numan y que odiaban a los turcos, se presentaron ante el Conde Raimundo para ofrecerle amistad, provisiones y otra ayuda ${ }^{8}$.

Pedro Tudebodo no menciona este incidente de las expediciones para recoger provisiones; pero el arzobispo Guillermo de Tiro lo describe diciendo que el Conde Raimundo «in terras hostium escendit, ut vitae necessaria plebi quocumque periculo procuraret. Ingressus igitur cum ma-

6 The Deeds of the Franks and the Other Pilgrims to Jerusalem, ed. R. Hill, Edinburgh 1962, pág. 30; "Roberti Monachi Historia Jherosolimitana", en RHC Occ Vol. III, Paris 1866, pág. 778; «Baldrici episcopi Dolensis Historia Jerosolimitana», en RHC Occ, Vol. IV, pág. 42; Guillermo de TIRO; "Historia Rerum in Partibus Transmarinis Gestarum", en RHC OcC, Vol. I, parte I, pág. 182.

7 Le «Liber» de Raymond d'Aguilers, ed. J.H. Hill y L.L. Hill, Paris 1969, págs. 50, 51; también ed. RHC Occ, Vol. III, págs. 243, 244.

8 Runciman, Ob. cit., págs. 260-270. 
ximo comitatu regionem hostium opulentissiman... greges inde retulit et armenta, servosque et ancillas et alimentorum ingentes copias" ${ }^{9}$.

En cambio, al relatar el mismo incidente, Raimundo de Aguilers dice "Cum vero vidisset comes quod nulli de principibus maioribus ad se venirent, et omnem populum fere contabescere cerneret, in interiora Ispanie pro victualibus populum ire precepti» ${ }^{10}$.

Raimundo no es el único autor que emplea la palabra Hispania en este sentido, al referirse a los incidentes de diciembre de 1097 y de enero de 1099. En 1100 el arzobispo Daimberto de Pisa y los demás jefes de la cruzada mandaron al Papa Pascual II un informe sobre la cruzada en el cual, hablando de la salida de Maarat, dicen "Deinde cum divino monitu in interiora Hispaniae progrederemar, largissiman atque misericordem et victoriosam manum omnipotentis Patris habuimus. Etenim cives et castellani regionis per quam procedebamus ad nos cum multis donariis legatos praemittebant parati servire et oppida sua reddere." ${ }^{11} \mathrm{EI}$ anónimo monje de Florennes, hablando de la salida de Maarat, dice «Exercitus Dei, divino monitu, in interiora Hispaniae profectus, larga Dei manu refocillatus est, quia cives et castellani illius regionis legatos cum multis donariis ad eos praemittebant, parati etiam oppida vel urbes eis tradere " ${ }^{2}$. Y Ekkehard, abad de Aura, dice «Inde cum divino nutu in interiora Hispaniae progrederentur, largissimam atque misericordem et victoriosissiman manum Omnipotentis Patris secum habuerunt. Etenim cives et castellani regionis illius per quam procedebant, ad eos cum multis donariis legatos praemittebant, parati servire et oppida sua reddere. Sed quia exercitus non multus erat, eit in Jherusalem unanimiter festinabant, acceptis securitatibus, tributarios eos fecerunt.» Además, un manuscrito entre los varios de la crónica de Ekkehard, tiene, en vez de estas últimas tres palabras, la lectura "Hispanos tributarios fecerunt» ${ }^{13}$.

Como es natural, la presencia del topónimo Hispania en estas crónicas de las cruzadas fue advertida por sus editores. Está claro que la palabra no puede referirse a la Península ibérica; pero tampoco es acep-

$\because$ G. de TIRO, Ob. cit., pág. 294.

10 Le «Liber» de Raymond d'Agullers, Ob. cit., pág. 101; ed. RHC Occ., vol. III, pág. 272.

J.P. MIGNe: Patrologia latina, vol. CLXIII, col. 449.

"Anonymi Florinensis brevis narratio belli sacri», in $R H C$ Occ., vol. V, pág. 372.

“Ekkehardi abbatis Uraugiensis Hierosolymita» en RHC Occ., vol. V, pág. 23. 
table la sugerencia que la relaciona con el topónimo pérsico, Ispaham ${ }^{14}$. Una razzia de 1.500 kilómetros desde Antioquía a Ispahan para buscar provisiones es casi tan increíble como una de 3.500 kilómetros a las costas catalanas. Se sabe que Raimundo de Aguilers emplea la palabra Hispania a veces para significar la Península ibérica; pero en los párrafos citados anteriormente, es evidente que quiere significar otra cosa. Donde él dice Hispania, Pedro Tudebodo, Roberto el Monje, Guillermo de Tiro y el autor anónimo de las Gesta Francorum, emplean las frases «terra Sarracenorum" o "hostium terras". Es obvio que todos quieren decir lo mismo, es decir, "tierra de musulmanes". No «la tierra ibérica de musulmanes», por supuesto, sino cualquier tierra dominada por musulmanes, cualquier "tierra de moros." También es obvio que Raimundo no es el único autor en emplear la palabra Hispania con este sentido, ya que lo hacen más tarde Ekkehard y el monje de Florrenes; y todos ellos lo emplean con cierta independencia de criterio.

Pero, ¿de dónde procede este empleo tan raro de dicha palabra? Un editor de la crónica de Ekkehard sugiere que los cruzados confundían las dos Hispanias, ambas ocupadas por los sarracenos, una en el Occidente y la utra en el Oriente; pero esto parece poco probable, ya que los cruzados conocían muy bien la diferencia entre Siria y la Península ibérica ${ }^{15}$.

Otro editor sugirió que quizás a Raimundo de Aguilers el topónimo Hispania le sonase igual que Sarracenica o Paganimitas, sugerencia que no es necesario comentar ${ }^{16}$. Refinando esta idea poco plausible, los profesores Hill han sugerido que los cruzados emplearian para la tierra de los musulmanes una palabra como paienie o pagienie, y que tal palabra podía convertirse en Ispania, por error de algún copista ${ }^{17}$. Es cierto que la Estoire d'Eracles, traducción francesa de la crónica de Guillermo de Tiro, relata la expedición por el valle de Orontes de 1097, con las palabras «alassent bien parfont en la paiennime»; y es muy probable que los cruzados francos hubieran empleado paiennime u otra palabra parecida para indicar los estados musulmanes. Sin embargo, parece poco probable que Raimundo de Aguilers, al escribir su crónica en latín, hubiera

14 Ibidem, pág. 23.

15 lbidem, pág. 23.

16 R. de AgulLERS; «Historia Francorum qui ceperunt Jerusalem» en RHC Occ., vol. III, pág. 243.

17 Le "Liber" de Raymond d'Aguilers, Ob. cit., pág. 13. 
insertado innecesariamente una palabra francesa, y que esta palabra hubiera sido sustituido por Hispania en todos y cada uno de los siete manuscritos independientes que se conservan de su obra.

Creemos que habrá que buscar la solución en otro lado. Varios cruzados habian luchado en España antes de participar en la primera cruzada a Jerusalén, y sin duda entre ellos había muchos vasallos del Conde Raimundo de Tolosa, vecinos de Aragón y de Cataluña ${ }^{18}$. Es muy posible que durante alguna campaña por el valle del Ebro hayan tomado de sus compañeros catalanes o aragoneses, la costumbre de referirse a la tierra de los moros con el topónimo España; y en este caso, no sería improbable que hubiesen mantenido esta costumbre lingüística en su campaña por Anatolia y Siria. Sin embargo, sería necesaria una investigación más extensa en las crónicas y documentos de Francia, y en las canciones de gestas para ver cómo emplean estas fuentes el topónimo España, antes de poder considerar resuelto el problema. Mientras tanto, lo ofrezco aquí como pequeño homenaje y señal de agradecimiento al profesor don Eloy Benito Ruano, historiacior eminente y entrañable amigo, cuyas obras durante varias décadas han iluminado la historia de las cruzadas, tanto en Tierra Santa como en España.

18 Referencias a sus experiencias en España en Le "Liber" de Raymond d"Aguilers, pág. 53; P. Tudebodus, Ob. cit., ed. J.H. Hill y L.L. Hill, Paris 1977, pág. 69. 
